OPEN ACCESS

Edited by:

Davide Zannoni,

University of Bologna, Italy

Reviewed by:

Oana Ciofu,

University of Copenhagen, Denmark

Dinesh Sriramulu,

Independent Researcher, Chennai,

India

${ }^{*}$ Correspondence:

lan T. Paulsen

ian.paulsen@mq.edu.au

${ }^{\dagger}$ These authors have contributed equally to this work

Specialty section:

This article was submitted to Microbial Physiology and Metabolism,

a section of the journal

Frontiers in Microbiology

Received: 06 March 2019

Accepted: 13 May 2019

Published: 31 May 2019

Citation:

Kumar SS, Penesyan A

Elbourne $L D H$, Gillings MR and

Paulsen IT (2019) Catabolism of Nucleic Acids by a Cystic Fibrosis Pseudomonas aeruginosa Isolate: An Adaptive Pathway to Cystic Fibrosis

Sputum Environment.

Front. Microbiol. 10:1199.

doi: 10.3389/fmicb.2019.01199

\section{Catabolism of Nucleic Acids by a Cystic Fibrosis Pseudomonas aeruginosa Isolate: An Adaptive Pathway to Cystic Fibrosis Sputum Environment}

\author{
Sheemal Shanista Kumar ${ }^{1 \dagger}$, Anahit Penesyan ${ }^{1 \dagger}$, Liam Davin Hunt Elbourne ${ }^{1}$, \\ Michael R. Gillings ${ }^{2}$ and lan T. Paulsen ${ }^{1 *}$
}

'Department of Molecular Sciences, Macquarie University, Sydney, NSW, Australia, ${ }^{2}$ Department of Biological Sciences, Macquarie University, Sydney, NSW, Australia

Pseudomonas aeruginosa is a major cause of morbidity and mortality in patients with cystic fibrosis (CF). We undertook Biolog Phenotype Microarray testing of $P$. aeruginosa $\mathrm{CF}$ isolates to investigate their catabolic capabilities compared to $P$. aeruginosa laboratory strains PAO1 and PA14. One strain, PASS4, displayed an unusual phenotype, only showing strong respiration on adenosine and inosine. Further testing indicated that PASS4 could grow on DNA as a sole carbon source, with a higher biomass production than PAO1. This suggested that PASS4 was specifically adapted to metabolize extracellular DNA, a substrate present at high concentrations in the CF lung. Transcriptomic and proteomic profiling of PASS4 and PAO1 when grown with DNA as a sole carbon source identified a set of upregulated genes, including virulence and hostadaptation genes. PASS4 was unable to utilize N-Acetyl-D-glucosamine, and when we selected PASS4 mutants able to grow on this carbon source, they also displayed a gain in ability to catabolize a broad range of other carbon sources. Genome sequencing of the mutants revealed they all contained mutations within the purK gene, encoding a key protein in the de novo purine biosynthesis pathway. This suggested that PASS4 was a purine auxotroph. Growth assays in the presence of $2 \mathrm{mM}$ adenosine and the complementation of PASS4 with an intact purK gene confirmed this conclusion. Purine auxotrophy may represent a viable microbial strategy for adaptation to DNA-rich environments such as the CF lung.

Keywords: Pseudomonas aeruginosa, cystic fibrosis, auxotrophy, carbon catabolism, biolog

\section{BACKGROUND}

Pseudomonas aeruginosa is an opportunistic pathogen associated with complications in cystic fibrosis (CF) and is a major cause of death among CF patients. We found that $P$. aeruginosa CF isolate PASS4 has very limited carbon catabolism capabilities and may have become specialized at utilizing nucleic acids as a source of carbon. The CF lung contains viscous sputum which includes an abundance of DNA from epithelial and bacterial cells, and therefore provides an excellent 
niche for such an adaptation. We found that many $P$. aeruginosa virulence genes have increased expression in response to external DNA. Characterization of $P$. aeruginosa PASS4 revealed that the molecular basis of its metabolic specialization is a defect in biosynthesis of purines, precursors for DNA synthesis. Better understanding of $P$. aeruginosa adaptations in the CF lung will help in the development of specialized treatment regimes aimed at eradication of $P$. aeruginosa infections.

\section{INTRODUCTION}

Cystic fibrosis (CF) is a genetic disorder most common among Caucasian populations (Petrova and Sauer, 2009). It is caused by mutations in the cystic fibrosis transmembrane regulator (CFTR) gene which encodes a cAMP-dependent chloride channel (Vankeerberghen et al., 2002). Dysfunction in the chloride channel leads to dehydrated and thickened airway surface liquid (ASL) hampering mucociliary clearance from the conducting airways (Mall, 2008). The thickened ASL enhances microbial colonization, leading to continuous stimulation of the immune system, and resulting in chronic lung inflammation (Sadikot et al., 2005). This hyperactive inflammatory response leads to a decline in lung function and eventual lung failure (Gellatly and Hancock, 2013).

Pseudomonas aeruginosa is one of the primary causes of acute and chronic lung infections in CF patients, resulting in significant morbidity and mortality (Wagner and Iglewski, 2008; Petrova and Sauer, 2009; Folkesson et al., 2012). P. aeruginosa is a metabolically versatile Gram-negative opportunistic pathogen that is common in various environments, such as soil and water (Wagner and Iglewski, 2008; Gellatly and Hancock, 2013). It can metabolize a broad range of carbon sources and grows both aerobically and anaerobically (Wagner and Iglewski, 2008; Mulcahy et al., 2010). Its metabolic versatility is conferred by a diverse set of transport systems and catabolic pathways encoded within a relatively large genome, typically more than $6 \mathrm{Mb}$ (Winstanley et al., 2016).

Most CF patients who develop a lung infection by adolescence can live with the infection for 20 or more years (Gellatly and Hancock, 2013). During this period, P. aeruginosa continues to adapt to the CF lung environment. This results in the emergence of diverse phenotypes including traits such as increased mucoidy, auxotrophy, loss of motility, emergence of hypermutators, resistance to antimicrobials, and defects in key virulence factors such as quorum sensing regulation and type III secretion (Wagner and Iglewski, 2008; Folkesson et al., 2012; Gellatly and Hancock, 2013; Winstanley et al., 2016).

Adaptation and chronic or recurrent infection of $P$. aeruginosa in the CF lung is facilitated by its ability to grow as biofilms (Wagner and Iglewski, 2008). Biofilms are highly organized, structured bacterial communities attached to one another, and/or to an inert or living surface (Wagner and Iglewski, 2008; Petrova and Sauer, 2009; Gellatly and Hancock, 2013). Cells in biofilms are held together by a matrix of extracellular polymeric substances (EPS) consisting mainly of polysaccharides, extracellular DNA (eDNA), lipids, proteins, cellular debris, and membrane vesicles (Wagner and Iglewski, 2008; Gellatly and Hancock, 2013; Haussler and Fuqua, 2013; Turnbull et al., 2016). EPS protect bacterial cells from damage or death caused by surfactants, biocides, grazing predators and host defenses (Wagner and Iglewski, 2008; Flemming and Wingender, 2010).

Extracellular DNA plays an adhesive role in the initial stages and development of $P$. aeruginosa biofilms (Wagner and Iglewski, 2008; Mulcahy et al., 2010; Turnbull et al., 2016). The source of eDNA has been proposed to be due to either prophageinduced cell lysis or the release of membrane vesicles which contain DNA (Kadurugamuwa and Beveridge, 1995; Turnbull et al., 2016). Investigations into $P$. aeruginosa eDNA release by Turnbull et al. (2016) suggests explosive cell lysis-mediated MV production in biofilms and planktonic cultures are independent of the Pseudomonas Quinolone Signal.

Extracellular DNA in CF lungs is derived from both microorganisms, and also lysed host cells (Finkel and Kolter, 2001; Haussler and Fuqua, 2013). The concentration of eDNA in the CF lung can be as high as $14 \mathrm{mg} / \mathrm{ml}$ (Finkel and Kolter, 2001; Das et al., 2015) and could serve as an abundant nutrient source for bacterial growth (Finkel and Kolter, 2001; Haussler and Fuqua, 2013). P. aeruginosa, Escherichia coli, and Shewanella spp. have all been shown to be able to utilize DNA as a nutrient source (Finkel and Kolter, 2001; Pinchuk et al., 2008; Mulcahy et al., 2010; Lewenza, 2013).

We recently described $P$. aeruginosa CF isolates (PASS1-4) that showed significant variability in colonization and virulencerelated traits (Penesyan et al., 2015). To investigate the metabolic capabilities of these strains, their ability to respire on 190 carbon sources was tested (Figure 1). One of the strains examined, PASS4, had lost the ability to utilize a broad range of carbon sources, and strong respiration was only observed on the purines inosine and adenosine. We found that PASS4 grew better on eDNA compared with other P. aeruginosa strains such as PAO1, suggesting that this strain may have become specialized for growth on DNA in the CF lung. Transcriptomic and proteomic analysis of PASS4, and genome sequencing of PASS4 mutants were undertaken to investigate the molecular basis of this metabolic specialization.

\section{RESULTS AND DISCUSSION}

\section{Phenotypic Comparison of $P$. aeruginosa CF Isolates PASS1-4}

We used Biolog Phenotype Microarrays to compare the carbon utilization profiles of four $P$. aeruginosa CF isolates (PASS1-4) with two $P$. aeruginosa model strains (PAO1 and PA14). Strains were screened for their ability to utilize 190 sole carbon sources, including a range of carbohydrates, amino acids, carboxylic acids and miscellaneous compounds (Bochner et al., 2001). $P$. aeruginosa strains PAO1, PA14, and PASS1 had similar metabolic fingerprints. The other three CF isolates (PASS2-4) displayed reduced capabilities for carbon utilization (Figure 1). In particular, PASS4 showed a striking reduction in catabolic capability, only showing strong respiration on two compounds, 


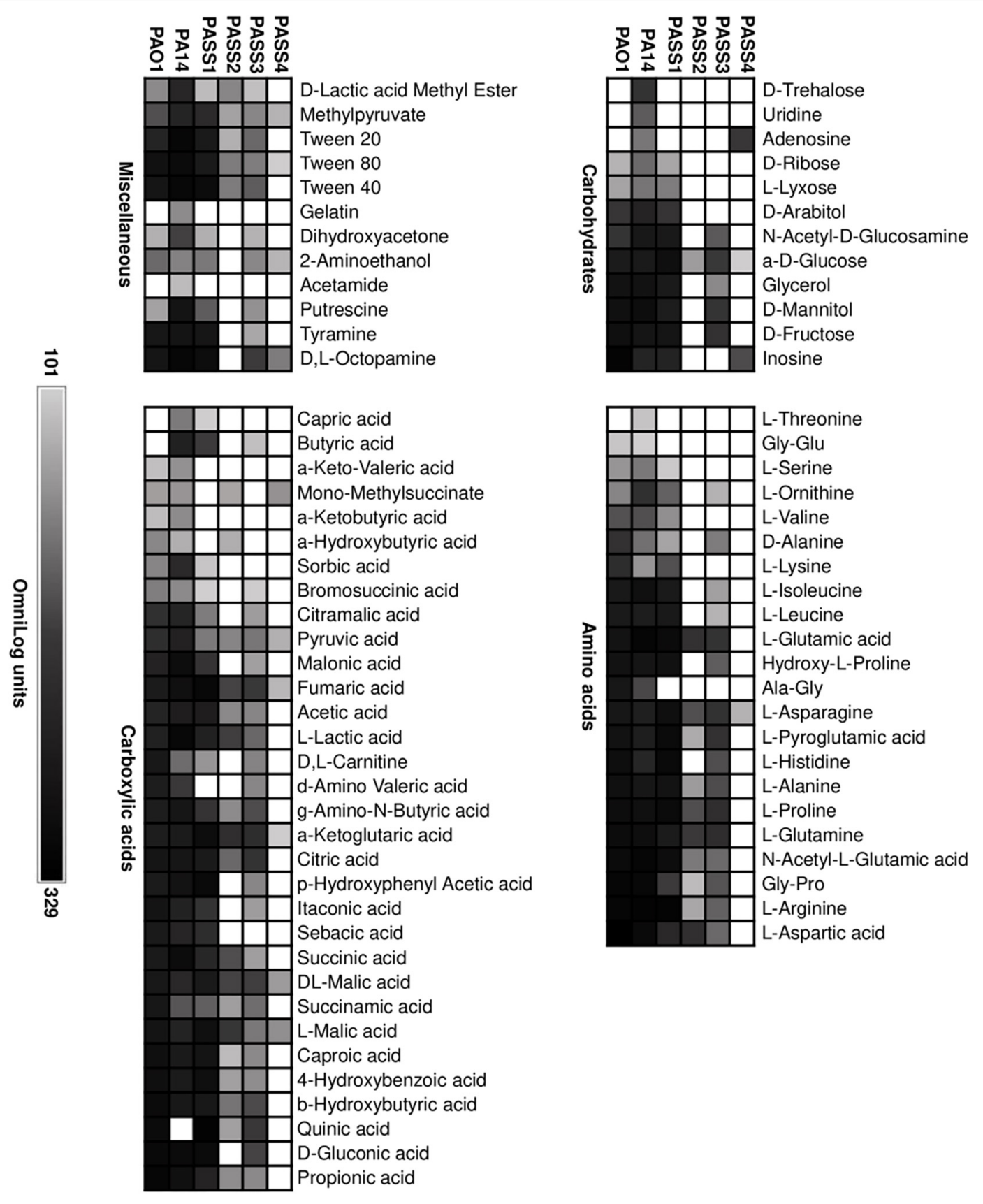

FIGURE 1 | The catabolic phenome of $P$. aeruginosa wild-type strains. The maximal kinetic curve height of $P$. aeruginosa wild-type strains is expressed as a grayscale ranging from 101 (gray) to 329 (black) OmniLog units following growth at $37^{\circ} \mathrm{C}$ for $48 \mathrm{~h}$. Phenotypes $<101$ OmniLog units (white) showed no detectable respiration.

the nucleosides adenosine and inosine. The capacity of PASS4 to grow on nucleosides was confirmed by culturing PASS4 on solid M9 minimal medium supplemented with $13 \mathrm{mM}$ adenosine as a sole carbon source.

The carbon utilization profiles of PASS2-4 suggest that reduction in metabolic capabilities might be a common adaptation for $P$. aeruginosa in the CF lung. Biolog phenotype testing of $35 P$. aeruginosa $\mathrm{CF}$ isolates in a previous study showed that metabolic reduction was common in CF isolates, with extensive heterogeneity amongst substrate utilization profiles (Jorgensen et al., 2015).

We hypothesized that PASS4 might be specialized to grow on DNA, which can be readily found in the CF lung environment. To investigate this possibility, PASS4 and PAO1 were grown in M9 minimal medium supplemented with $1.5 \mathrm{mg} / \mathrm{ml}$ of salmon sperm DNA (Sigma, United States) as a sole carbon source. Based on optical density measurement at $\mathrm{OD}_{600}$, the total biomass of PASS4 cells was $18 \%$ greater than PAO1 following growth in 
DNA over 7 days with constant aeration at $37^{\circ} \mathrm{C}$. Dandekar et al. (2012) have observed the strain PAO1 to have a doubling time greater than $40 \mathrm{~h}$ when grown in adenosine as a sole carbon source (Dandekar et al., 2012). Both strains tested negative for production of extracellular DNase, suggesting that they uptake DNA where it is subsequently degraded intracellularly.

\section{The Transcriptome and Proteome of PAO1 and PASS4 Following Growth in DNA}

The global transcriptional response and protein abundance of $P$. aeruginosa strains PASS4 and PAO1 grown to an $\mathrm{OD}_{600}=0.6$ with DNA as a sole carbon source was assessed using RNA sequencing (Table 1) and whole-cell proteomics. Growth on asparagine was used as a control, since this was one of the few carbon sources that PASS4 was able to utilize, according to the Biolog Phenotype Microarray analysis (Figure 1).

The transcriptomic analysis identified a total of 576 genes that were differentially transcribed by PASS4 when grown in the presence of DNA $\left(P\right.$-value $<0.01, \log _{2}$ fold-change $1<$ to $<-1$ ), with 322 genes upregulated and 254 genes downregulated (Supplementary Figure S1 and Supplementary Table ST1). There were a total of 423 genes differentially expressed by PAO1 when grown in DNA ( $P$-value $<0.01, \log _{2}$ fold-change $1<$ to $<-1)$, with 359 genes upregulated and 64 genes downregulated (Supplementary Figure S2 and Supplementary Table ST1). The transcriptional response of PASS4 and PAO1 grown in DNA in comparison to growth in asparagine had a correlation value of $R^{2}=0.5983$ (Figure 2A). A total of 129 transcripts displayed similar expression patterns in both organisms, with 112 being upregulated and 17 downregulated (Supplementary Table ST1). Among the most noticeable differences, the two strains displayed differential expression of a hypothetical protein (PA3783), which was downregulated 3-fold in PAO1 and upregulated 4-fold in PASS4 during growth in DNA.

The shotgun proteomic analysis detected a total of 1962 proteins in PASS4, of which 307 displayed significant differential

TABLE 1 | Summary of $P$. aeruginosa PAO1 and PASS4 mapped reads following growth in DNA or asparagine.

\begin{tabular}{lccc}
\hline Condition & Replicate & Paired reads & $\begin{array}{c}\text { Percentage } \\
\text { aligned }\end{array}$ \\
\hline PAO1 grown in Asparagine & 1 & 14532003 & 98.80 \\
& 2 & 11886289 & 98.77 \\
PAO1 grown in DNA & 3 & 12821286 & 98.95 \\
& 1 & 13805330 & 80.69 \\
PASS4 grown in Asparagine & 2 & 12869272 & 89.53 \\
& 3 & 12660666 & 89.75 \\
PASS4 grown in DNA & 1 & 11436333 & 97.95 \\
& 3 & 13152398 & 97.08 \\
& 1 & 11153482 & 97.96 \\
& 2 & 11846213 & 92.70 \\
& 3 & 11599891 & 91.39 \\
& & 12826627 & 86.20
\end{tabular}

abundance between the two conditions $\left(P<0.05, \log _{2}\right.$ fold-change $1<$ to $<-1$ ) (Supplementary Figure S3 and Supplementary Table ST1). A total of 239 proteins showed greater abundance when the cells were grown on DNA as a sole carbon source in comparison to 68 proteins which displayed a decrease in abundance. A total of 2112 proteins were detected from PAO1, of 293 proteins were significantly differentially abundant $\left(P<0.05, \log _{2}\right.$ fold-change $1<$ to $\left.<-1\right)$, with an increase in abundance of 232 and decrease in abundance of 61 proteins (Supplementary Figure S4 and Supplementary Table ST1). A correlation analysis of the protein expression of PAO1 and PASS4 grown in DNA presented an $R^{2}$ value of 0.4072 (Figure 2B). Only six proteins showed significant differences in protein abundance between PAO1 and PASS4 (Figure 2B), among those a C5 dicarboxylate transporter showed an 6.5-fold increase in abundance in PAO1 but showed a 10.9-fold decrease in abundance in PASS4 when these strains were grown in DNA.

\section{Increased Expression of Iron and Sulfate Acquisition Genes in Response to DNA}

The pyoverdine $(p v d)$ and pyochelin $(p c h)$ biosynthetic gene clusters encode the two major P. aeruginosa siderophores (Yeung et al., 2014; Lee and Zhang, 2015). Expression of the pch gene cluster and pyochelin receptor $(f p t A)$ was significantly induced by exposure to DNA in both PAO1 and PASS4 (Figure 3). The $p v d$ gene cluster was significantly upregulated by DNA in PAO1, but not in PASS4 (Figure 3). PASS4 grown in DNA displayed a significant increase in the abundance of the PvdE and PvdF proteins. The iron-responsive small RNAs PrrF1 and PrrF2 (Wang et al., 2012) were upregulated in both PASS4 (11-fold and 19-fold, respectively) and PAO1 (both by 6-fold) (Figure 3 ). During iron limitation, these small RNAs enable inhibition of genes that encode "non-essential" iron-containing proteins (Smith, 2015). Additionally, PASS4 grown in DNA displayed an increased abundance of iron acquisition proteins including the putative TonB-dependent receptor family protein (PA0781), TonB-dependent siderophore receptor (PA4837), FeoB $\mathrm{Fe}^{2+}$ transporter (PA4358), FecA ferric citrate receptor (PA3901) and FiuR iron transport protein.

DNA as a sole carbon source led to the upregulation of an array of genes involved in sulfate metabolism in both PASS4 and PAO1. For example, the tauABC genes, encoding an $\mathrm{ABC}$ transporter for the sulfate-containing amino acid taurine were upregulated more than 2- fold in both PASS4 and PAO1. The tauD gene, encoding taurine dioxygenase was upregulated more than 2 -fold and had an 8 -fold increase in protein abundance in PASS4. The expression of $(\tan A B C D)$ is known to be regulated by sulfate starvation (van der Ploeg et al., 1996). Expression of other genes involved in the utilization of alternate sulfate sources, such as alkane sulphonates, were also increased in the presence of DNA. The lsfA gene encoding a thio-specific antioxidant was upregulated 4-fold in PASS4 and 30-fold in PAO1 following growth in DNA.

Sulfate regulatory systems also showed significant changes in gene expression in DNA grown cells. The ECF sigma factor PA2093 was 8-fold upregulated by DNA in PASS4. This sigma 
A

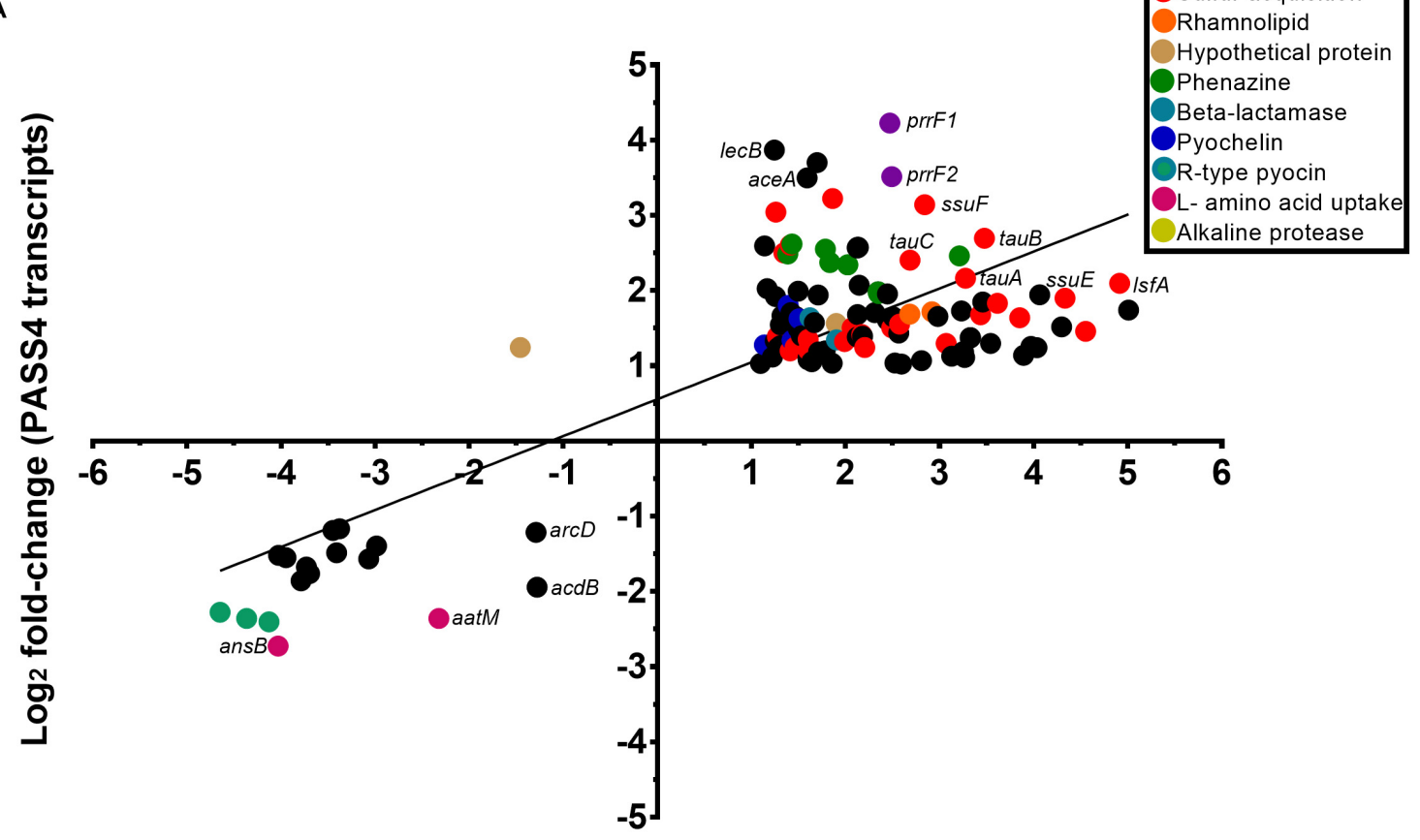

Log2 fold-change (PAO1 transcripts)

B

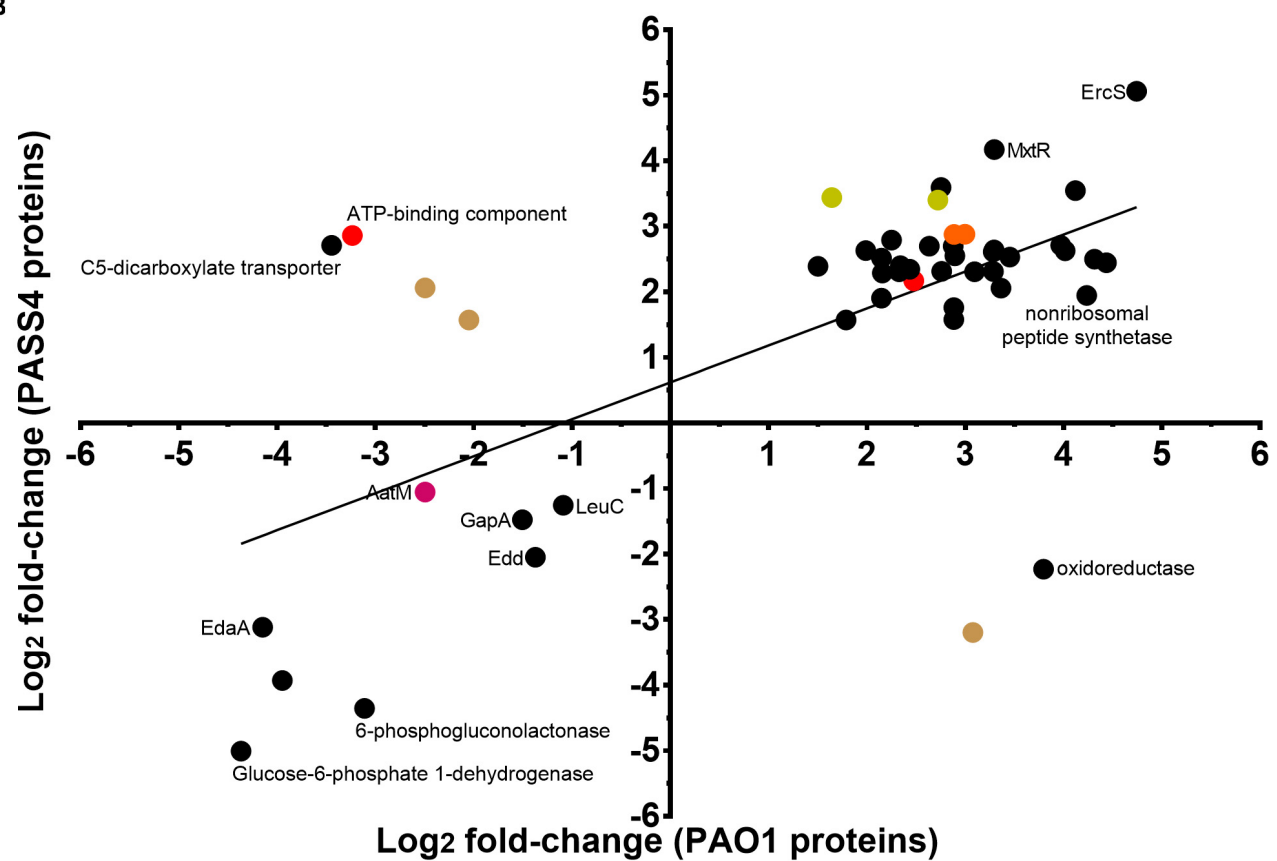

FIGURE 2 | Comparison of the changes in expression at a transcript and protein level in P. aeruginosa PASS4 and PAO1 following growth in DNA; growth in asparagine was used as a reference. (A) The chart shows $\log _{2}$ fold changes of transcript data from RNA-sequencing $\left(P<0.01, \log _{2}\right.$ fold-change $1<$ to $\left.<-1\right)$. Correlation of PASS4 and PAO1 transcript data was moderately similar $\left(R^{2}=0.5983\right)$. (B) The chart shows $\log _{2}$ fold changes of shotgun protein data $(P<0.05$, log 2 fold-change $1<$ to $<-1)$. Correlation of PASS4 and PAO1 protein data was moderately similar $\left(R^{2}=0.4072\right)$. 

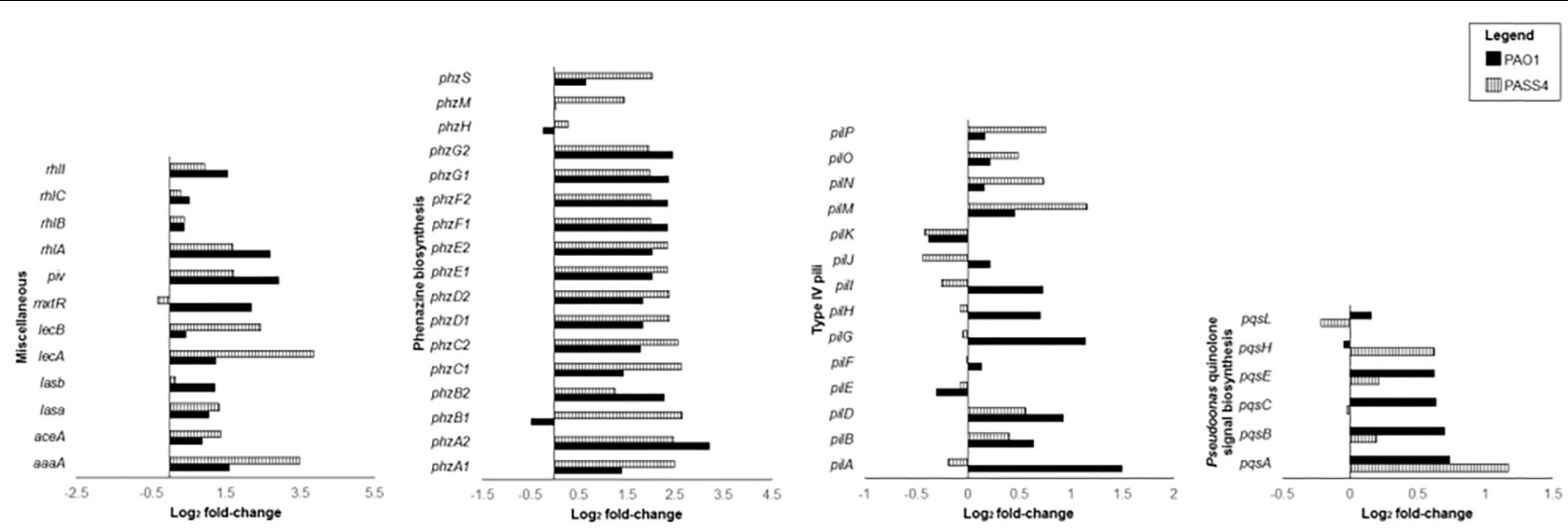

FIGURE 3 | Differential gene expression ( $\log _{2}$ fold-change) of virulence genes when $P$. aeruginosa strains PASS4 and PAO1 were grown in DNA compared to asparagine.

factor has previously been shown to be upregulated by sulfate limitation (Tralau et al., 2007). Typically, the TonB-dependent transducers PA2089 and PA2590 (both have increased protein abundance and significant upregulation of transcripts in PASS4 grown in DNA) sense an extracellular signal which is transmitted via the anti-sigma factor leading to the activation of ECF sigma factor (PA2093) and to the subsequent transcription of target genes such as PA2090 (upregulated significantly in PAO1 and PASS4 grown in DNA). The putative sulphonatase (PA2090) is part of a predicted extracellular sulfate (ECS) locus (PA2083PA2094) (Robinson, 2013). All members of the ECS locus were upregulated at the transcriptional level in PASS4, with some upregulated in PAO1. The protein abundance of members of the ECS locus was also increased in PASS4.

During growth, most heterotrophic bacteria are known to maintain specific elemental ratios of carbon, nitrogen, sulfate, phosphorus and iron (Gray, 2017). Compared to most other carbon sources, DNA is a rich source for nitrogen and phosphorus. Thus, the increased expression of genes for iron and sulfate acquisition may reflect an attempt by Pseudomonas cells to balance their elemental ratios in a phosphorus/ nitrogen rich setting.

\section{Increased Expression of Virulence Related Genes in Response to eDNA}

The set of genes that were induced at least 4-fold by DNA in both PAO1 and PASS4 included two clusters of phenazine biosynthesis genes phzA1B1C1D1E1F1G1 and phzA2B2C2D2E2F2G2 (Figure 3). Several genes from the phz1 and phz2 gene clusters had significant increases in protein abundance in PAO1. Phenazine redox pigments such as pyocyanin and 1-hydroxyphenazine are important virulence factors: 1-hydroxyphenazine constrains mammalian cell respiration; and pyocyanin hinders epidermal cell growth and plays a role in acquisition of iron from transferrin (Wilson et al., 1988). Pyocyanin has also been shown to bind directly to the phosphate backbone of DNA, altering the viscosity of DNA solutions.
During biofilm growth, by interacting with DNA, pyocyanin can facilitate electron transfer through DNA for maintenance of redox homeostasis between anoxic and oxygenated regions of the biofilms (Kempes et al., 2014; Das et al., 2015).

The RhlR quorum-sensing system regulates the phenazine biosynthesis and receptor genes (Whiteley et al., 1999; Reis et al., 2011), elastase las $B$, protease las $A$, and rhamnolipid biosynthesis genes rhlAB (Pearson et al., 1997; Grosso-Becerra et al., 2014). The rhlR transcripts were upregulated in both PAO1 and PASS4 grown in DNA, rhlAB transcripts and proteins showed increased abundance in both PASS4 and PAO1 when grown on DNA (Figure 3). The las $A$ and $l a s B$ transcripts were upregulated in PASS4 and PAO1 grown in DNA, the protein abundance of LasA was significantly increased in PASS4 and LasB was significantly increased in PAO1.

The $m x t R$ (PA3271) gene encoding a sensor kinase was upregulated 5-fold in PASS4. The MxtR protein showed 8-fold and 16-fold increase in abundance in PAO1 and PASS4, respectively. MxtR has been shown to modulate the production of interbacterial 2-alkyl-4(1H)-quinolone (AQ) signal molecule via the LysR-type transcriptional regulator MexT (Zaoui et al., 2012) (no significant differential expression observed in our study). MxtR-induced AQ has an influence on the P. aeruginosa regulatory network, including the transcription of virulence genes coding for pyocyanin and rhamnolipids (Zaoui et al., 2012). PAO1 grown in DNA showed increased abundance of the PqsA, PqsE, and PqsL proteins (13-fold, 15-fold, and 3-fold, respectively). The $p q s A B C D E$ operon is positively regulated by the expression of 2-heptyl-4-hydroxyquinoline (HHQ) and is required for AQ biosynthesis (Rampioni et al., 2016). Although $p q s E$ does not play a role in AQ biosynthesis, it has been shown to influence the production of virulence factors such as pyocyanin, phenazines and rhamnolipids (Heeb et al., 2011).

A QS dependent lysine-specific endoprotease (Oh et al., 2017), piv was upregulated 4.5-fold when PAO1 grown in DNA. This protease has been shown to cause killing of Tenebrio molitor larvae within 4 days post infection (Park et al., 2014). PIV also play a role in scavenging for nutrients (Barbier et al., 2014). 
The lecB gene, encoding the fucose-binding lectin, showed 15-fold higher expression in PASS4 grown on DNA, but only twofold increased expression in PAO1 (Figure 3). The LecB lectin has been shown to have cytotoxic effects on host respiratory epithelial cells, and plays an important role in facilitating adhesion to the airway mucosa. The $l e c A$ gene encoding a galactose-binding lectin was not significantly differentially expressed in either PAO1 or PASS4 when grown in DNA. This was surprising, as a previous study (Kohler et al., 2005) has shown the induction of the lecA lectin by adenosine.

The type 4 pilus (T4P) transcripts pilA, pilG, and pilZ were upregulated in PAO1 grown in DNA. Following growth of PASS4 in DNA there was has an increase in expression of the pilM transcript and an increase in protein abundance of PilH and PilM. The T4P plays a role in cell adhesion, host cell invasion (Hahn, 1997), biofilm formation, as well as DNA uptake (Mattick, 2002; Craig and Li, 2008).

The aceA gene encoding isocitrate lyase (Hogardt and Heesemann, 2010), which is specific to the glyoxylate shunt pathway, is 11-fold upregulated in PASS4 and 3-fold upregulated in PAO1 when grown in DNA. The glycoxylate shunt is known to be upregulated under conditions of oxidative stress, antibiotic stress, and host infection (Ahn et al., 2016). The aceA gene has been shown to be critical for $P$. aeruginosa infection in an alfalfa seedling model (Lindsey et al., 2008).

An arginine-specific autotransporter, AaaA showed an 11-fold higher protein abundance, and 2-fold downregulation of the transcript in PAO1. Previously, a gene knockout of aaaA led to attenuation of $P$. aeruginosa in a mouse chronic wound infection suggesting it plays a role in virulence (Luckett et al., 2012).

\section{Other Transcriptional Changes in Response to DNA}

As expected, the ans $B$ gene, encoding L-asparaginase, showed 16-fold and 7-fold decrease in gene expression in DNA-grown cells compared with asparagine-grown cells for PAO1 and PASS4, respectively. Other genes in the same regulon as ans $B$, such as the aat $M$ gene, encoding for acidic L-amino acid uptake, were also upregulated by asparagine. The branched chain amino acid catabolism genes liuA, liuB, liuC, bkdA1, bkdA2, bkdB, lpdV, $m m s B$, and $m m s A$ were upregulated in asparagine-grown cells, suggesting a regulatory link between asparagine and branched chain amino acid degradation. The transport and utilization of branch chain amino acids, arginine and ornithine has been reported to be governed by the $\mathrm{CbrAB} / \mathrm{Crc}$ regulatory system (Sonnleitner et al., 2012).

The PA0622-PA0624 genes involved in the production of the R-type pyocin were downregulated by a more than 4 -fold in both PAO1 and PASS4 during growth in DNA compared to asparagine. These genes, along with other genes from the R- and F-pyocin gene cluster, encode a prophage endolysin which is essential for explosive cell lysis that leads to increased availability of public goods such as cytosolic proteins, eDNA, and membrane vesicles (Turnbull et al., 2016). The transcriptomic data suggests that the concentration of eDNA is an important factor regulating the expression of genes controlling explosive cell lysis.

\section{Carbon Utilization by $P$. aeruginosa Mutants}

The transcriptomic and proteomic analyses of PASS4 grown on DNA identified a broad range of genes whose expression might be regulated by DNA including many virulence factors. However, it did not provide any clear answers as to the molecular basis of metabolic specialization in PASS4. To further investigate the specialization of PASS4 for growth on DNA, we screened mutants of PASS4 to isolate strains that had broader substrate utilization capabilities. To obtain such mutants, we inoculated $P$. aeruginosa PASS4 on minimal M9 medium containing $20 \mathrm{mM} \mathrm{N}$-AcetylD-glucosamine (GlcNAc), a carbon source that PASS4 cells were unable to utilize (Figure 1). Within 7 days, spontaneous mutant colonies were observed and subsequently cultured into liquid M9 minimal salts medium containing $20 \mathrm{mM}$ GlcNAc. This culture was consecutively subcultured for 14 days until cells reached an $\mathrm{OD}_{600}=0.7$ within $35 \mathrm{~h}$. At the end of this process, we obtained eight $P$. aeruginosa PASS4 mutants which had gained the ability to grow on GlcNAc.

The eight mutants displayed much broader carbon catabolic profiles than the parental PASS4 strain when tested on Biolog Phenotype Microarray plates. All of these mutants had gained the ability to utilize a wide range of carbon sources including amino acids, carbohydrates and carboxylic acids (Figure 4). The substrate utilization profiles of the mutants resembled those of most $P$. aeruginosa strains, including PAO1, PA14, and PASS1. This dramatic change in carbon utilization capability suggests that the mutation(s) in these PASS4 mutants had apparently circumvented the genetic specialization in the parental PASS4 isolate that allowed it to grow well on DNA, but not on most other carbon sources.

\section{PASS4 Mutants Have Mutations in the purK Gene}

Genome sequencing was undertaken on the Miseq v2 platform of eight PASS4 mutants that had gained the ability to utilize GlcNAc and an array of other carbon sources. In parallel, we also resequenced the PASS4 genome as a reference. Bioinformatic analysis identified single nucleotide polymorphisms (SNPs) between the mutants and the PASS4 genome. All of the PASS4 mutants contained a mutation in the purK gene, located at codon 214 (for PASS4 mutants 2 and 3) or codon 354 (for PASS4 mutants 1 and 4 to 8) (Supplementary Table ST2 and Supplementary Figure S5). Additional SNPs were also detected in mutants 1 and 7 , in a chemotaxis transducer $(p c t B)$ and a hypothetical protein, respectively. The purK gene encodes a subunit of the phosphoribosylaminoimadazole carboxylase enzyme, a critical step in the de novo synthesis of purines (Zhang et al., 2008). This suggests that PASS4 is defective in purine biosynthesis, which explains why it grows well only on DNA and purines, while growing poorly, or not at all, on essentially all other tested carbon sources, as would be expected for a purine auxotroph.

To test whether the inability of PASS4 to grow on various carbon sources was due to a defect in purine biosynthesis, we repeated the Biolog phenotype testing but including 


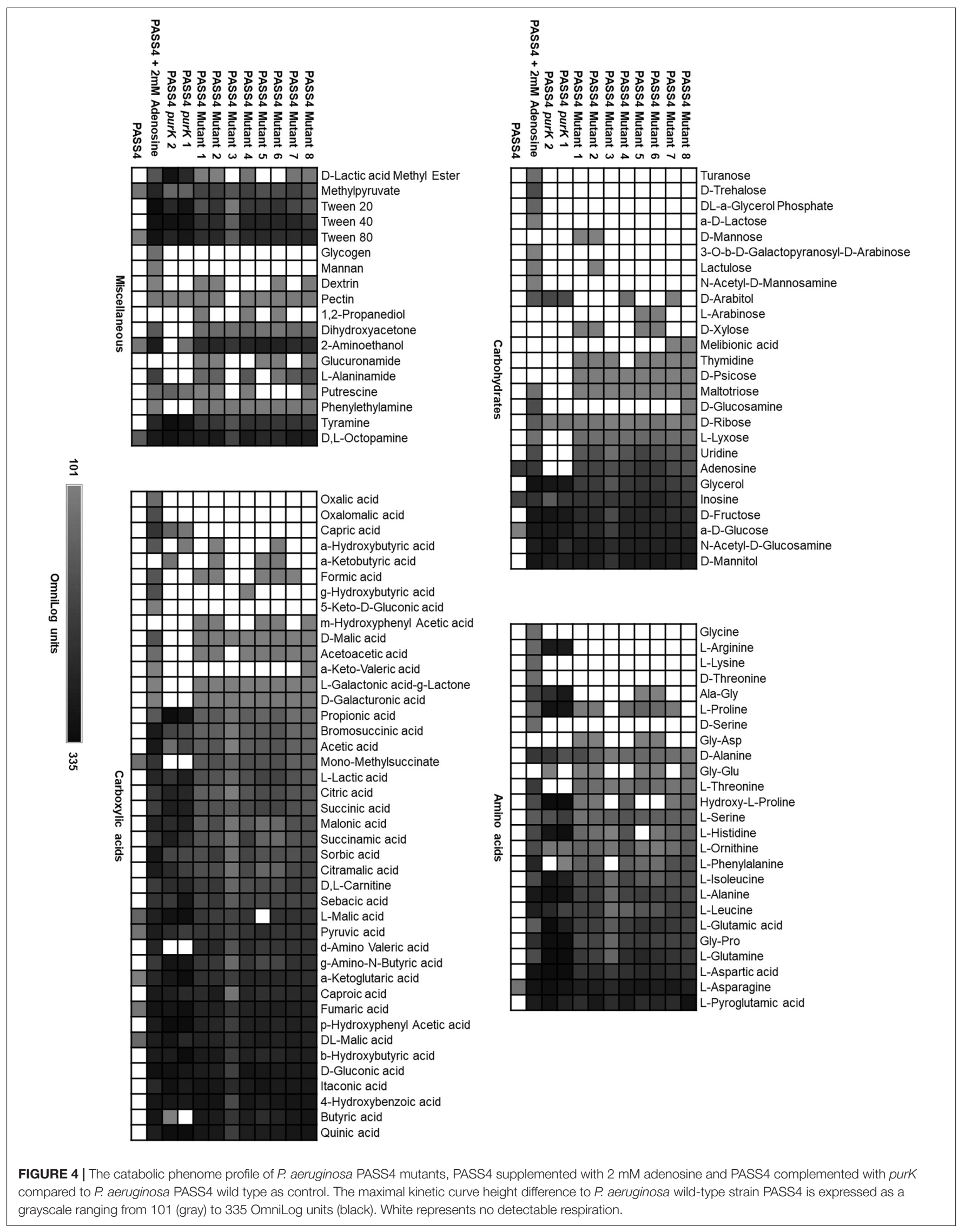


supplementation with $2 \mathrm{mM}$ adenosine. This concentration of adenosine was not sufficient as a sole carbon source to support the growth of PASS4. The supplementation of $2 \mathrm{mM}$ adenosine and complementation of PASS4 with purK enabled PASS4 to grow on a wide range of carbohydrates, amino acids, and carboxylic acids that it previously was unable to utilize (Figure 4). This provides evidence that the underlying growth defect in PASS4 is due to a defect in de novo purine biosynthesis. Since all of the PASS4 mutants had changes within the purK gene, it is highly likely that PurK is defective in PASS4.

The CF lung environment contains high concentrations of eDNA. The defect in purine biosynthesis in PASS4, coupled with an ability to grow faster on DNA as a sole carbon source compared with other $P$. aeruginosa strains, probably reflects a niche adaptation to this DNA-rich environment. Species from the genera Chlamydia and Rickettsia, the parasitic flagellate protozoa Trypanosoma, Treponema pallidum, Mycoplasma, Ureaplasma, Mesoplama, Borrelia, and even Lactobacillus, all appear to exist without the presence of the classical de novo purine nucleotide biosynthesis pathway (Zhang et al., 2008). These organisms are either obligate parasites or are associated with mucosal epithelial layers of the host (Zhang et al., 2008). Scavenging purines or nucleic acids from their host may be a common adaptation in many parasites, pathogens and commensals.

The PASS4 strain showed modest growth on asparagine as a sole carbon source. Indeed, this compound was used as a growth nutrient in the transcriptomic and proteomic experiments in this study. Asparagine is required for the conversion of inosine monophosphate to adenylosuccinate, in the first enzymatic step in dATP synthesis after de novo purine biosynthesis (Supplementary Figure S6). The ability of PASS4 to grow on asparagine as a sole carbon source could be due to high levels of asparagine enabling sufficient flux through the purine biosynthesis pathway to allow growth. In turn, this suggests a decrease in the efficiency of the PurK enzyme in PASS4, rather than a complete loss of function.

\section{CONCLUSION}

Phenotypic analysis revealed that the $P$. aeruginosa CF isolate PASS4 was only able to grow on a limited range of carbon sources, including purines and DNA. On these substrates it showed higher growth rates than other $P$. aeruginosa isolates. This suggested that this strain is specialized to live on eDNA available in the CF lung. We investigated the genetic basis of this apparent metabolic specialization. Transcriptomic and proteomic studies of $P$. aeruginosa PASS4 and PAO1 grown in DNA revealed that eDNA affected the expression of many genes, particularly virulence and host-adaptation genes. This suggests that eDNA may be an important signal in the CF lung for expression of virulence factors by $P$. aeruginosa.

The transcriptomic and proteomic expression analyses did not provide any direct insights into the metabolic specialization of PASS4. Genome sequencing of PASS4 mutants that had gained the ability to catabolize GlcNAc, as well as a wide range of unrelated carbon sources, indicated that they all contained mutations in the purK gene, which encodes a key enzyme in the de novo purine biosynthesis pathway. This suggested that PASS4 was a purine auxotroph, and this was confirmed by phenotypic testing showing addition of $2 \mathrm{mM}$ adenosine could rescue growth of PASS4 on a broad range of carbon sources. Purine auxotrophy may represent a viable microbial strategy for adaptation to DNA-rich environments such as the CF lung.

\section{MATERIALS AND METHODS}

\section{Pseudomonas aeruginosa Strains and Media}

Pseudomonas aeruginosa strains used for this study were PAO1 (Stover et al., 2000), PA14 (He et al., 2004) and PASS1-4 (Penesyan et al., 2015; Thaysen-Andersen et al., 2015). The PASS1-4 isolates were obtained from the sputum of CF patients at the Westmead Hospital (Sydney, Australia). The P. aeruginosa isolate PASS1 was obtained from a 40-year old female patient, PASS2 from a 27-year old male, PASS3 from a 23-year-old male and PASS4 from a 23-year old female (Penesyan et al., 2015; Thaysen-Andersen et al., 2015). These isolates were maintained in glycerol stocks at $-80^{\circ} \mathrm{C}$. P. aeruginosa isolates were routinely cultured on Luria Bertani (LB) media, solid or liquid, from the frozen stock, allowing minimum passages during cultivation.

\section{Production of Exoenzyme DNase}

The test for the production of exoenzyme DNase by $P$. aeruginosa PAO1 and PASS4 was conducted with a use of DNase test agar (Oxoid). Briefly, as per manufacturer's instructions, the strains were streaked on a DNase test agar plate and incubated at $37^{\circ} \mathrm{C}$ for $24 \mathrm{~h}$. The DNase test agar contained tryptose, DNA and $\mathrm{NaCl}$. The production of DNase leads to the hydrolysis of DNA in the media. Therefore, following incubation, the plates were flooded with $1 \mathrm{~N} \mathrm{HCl}$ to observe for a clearing/hydrolysis of DNA by the bacterium.

\section{RNA Extraction and RNA-Seq Transcriptomics}

Pseudomonas aeruginosa strains PAO1 and PASS4 were simultaneously inoculated into $5 \mathrm{ml}$ of LB liquid medium from the frozen stock and grown overnight. Overnight cultures were used to inoculate $15 \mathrm{ml}$ of M9 minimal medium supplemented with either L-Asparagine $(20 \mathrm{mM})$ or DNA (1.5 $\mathrm{mg} / \mathrm{ml}$ ) (Salmon sperm DNA, Sigma, United States), both in biological triplicates. Cultures were grown until midexponential phase $\left(\mathrm{OD}_{600}=0.6\right)$. RNA was extracted from these cultures using the miRNEasy RNA extraction kit (Qiagen) according to the manufacturer's protocol. To remove any residual genomic DNA, the samples were treated with DNAse using the TURBO DNAse kit (Invitrogen, United States). The quality and quantity of extracted RNA was assessed on a NanoDrop spectrophotometer. To remove highly abundant ribosomal RNA from the RNA extracts before sequencing, the samples were treated using RiboZero GN Magnetic rRNA depletion 
kit (Epicenter). The rRNA depleted samples were purified using RNeasy MinELute Cleanup kit (Qiagen, Germany) and re-assessed on NanoDrop and submitted to the Ramaciotti Centre for Genomics for paired-end RNA Sequencing on the HiSeq 2000 platform. Paired-end RNA Sequence files obtained from Ramaciotti were assessed for quality using FastQC software (Babraham Bioinformatics, United Kingdom) and processed by trimming the first 10 nucleotides using Fastx Toolkit. Trimmed sequences were tiled against the complete genome of PAO1 via EdgePro software (Magoc et al., 2013) and differential expression calculated using DESeq software (Anders and Huber, 2010). De novo transcript assembly and differential gene expression analysis was performed for PASS4 strain using the Rockhopper 2.03 tool (McClure et al., 2013; Tjaden, 2015) to supplement the data on PASS4 genes absent in PAO1 genome. The RNA-seq raw data reported here are accessible under the Gene Expression Omnibus submission accession number GSE100287.

\section{Protein Extraction and Label-Free Shotgun Proteomics}

Pseudomonas aeruginosa strains PAO1 and PASS4 were inoculated into M9 Minimal salts media with $100 \mu \mathrm{M}$ calcium chloride $\left(\mathrm{CaCl}_{2}\right)$ and $2 \mathrm{mM}$ magnesium sulfate $\left(\mathrm{MgSO}_{4}\right)$ containing either L-Asparagine $(20 \mathrm{mM})$ as a control condition or DNA $(1.5 \mathrm{mg} / \mathrm{ml})$ as an experimental condition. Cultures were grown aerobically $(n=3)$ at $37^{\circ} \mathrm{C}$ with constant shaking at $200 \mathrm{rpm}$. Overnight cultures were subcultured into the same respective medium, prior to harvesting cells in logarithmic phase $\left(\mathrm{OD}_{600}=0.6\right)$. For proteomic analysis, cells were harvested from $60 \mathrm{ml}$ of culture by centrifugation at $3220 \mathrm{~g}, 10 \mathrm{~min}$ at $4^{\circ} \mathrm{C}$ (Beckman centrifuge, United States). Cells were washed with phosphate buffered saline $(\mathrm{pH} 7.4)$ and stored at $-80^{\circ} \mathrm{C}$ until further processing. Proteins were extracted by lysing cell pellets with sodium dodecyl sulfate (SDS) lysis buffer $(2.3 \% \mathrm{w} / \mathrm{v}$ SDS, $0.12 \mathrm{M}$ Tris, $0.4 \mathrm{mM}$ EDTA, $4 \% \mathrm{w} / \mathrm{v}$ glycerol and $0.05 \%$ v/v $\beta$-mercaptoethanol ( $\mathrm{pH}$ 6.8). Followed by four $30 \mathrm{~s}$ rounds of bead beating at $5.5 \mathrm{~m} / \mathrm{sec}$ (FastPrep FP120, United States), with intermittent cooling. Cellular debris was removed by centrifugation at for $10,000 \times g$ for $10 \mathrm{~min}$ (Eppendorf, model $5804 \mathrm{R})$ and the supernatants were collected and stored at $-20^{\circ} \mathrm{C}$ for further processing. The extracted proteins were precipitated using a methanol/chloroform/water protocol (Wessel and Flugge, 1984). Resultant proteins pellets were resuspended in $1 \% \mathrm{w} / \mathrm{v}$ SDS, $13 \% \mathrm{w} / \mathrm{v}$ glycerol and $33 \mathrm{mM}$ Tris ( $\mathrm{pH}$ 6.8) and quantitated using a BCA Protein assay kit as per manufacturer's instructions (Thermo Fisher Scientific, United States). $30 \mu \mathrm{g}$ of each sample was diluted with sample loading buffer, [1\% w/v SDS, $13 \% \mathrm{w} / \mathrm{v}$ glycerol and $33 \mathrm{mM}$ Tris, $20 \mathrm{mM} \beta$-mercaptoethanol, $0.004 \%$ bromophenol blue ( $\mathrm{pH}$ 6.8)], denatured by boiling $\left(95^{\circ} \mathrm{C}, 4 \mathrm{~min}\right.$ ) and separated using SDS-PAGE (Bio-Rad, Australia). After electrophoresis, proteins were visualized using colloidal Coomassie Blue and processed further for tryptic digestion as detailed in Mirzaei et al. (2012). Briefly, each gel lane corresponding to individual sample was cut into 16 pieces, chopped and placed into a well of a 96-well plate. The gel pieces were briefly washed with $100 \mathrm{mM} \mathrm{NH}_{4} \mathrm{HCO}_{3}$, followed by washing twice with acetonitrile (ACN) (50\%)/100 mM NH $4 \mathrm{HCO}_{3}(50 \%)$ for $10 \mathrm{~min}$. Finally, gel pieces were dehydrated with $100 \%$ ACN and air-dried. Proteins were reduced with $10 \mathrm{mM}$ dithiothreitol (DTT) in $\mathrm{NH}_{4} \mathrm{HCO}_{3}(50 \mathrm{mM})$ at $37^{\circ} \mathrm{C}$ for $1 \mathrm{~h}$, followed by alkylation with $50 \mathrm{mM}$ iodoacetamide in $\mathrm{NH}_{4} \mathrm{HCO}_{3}(50 \mathrm{mM})$, in the dark at RT for $1 \mathrm{~h}$. Samples were then washed with $100 \mathrm{mM}$ $\mathrm{NH}_{4} \mathrm{HCO}_{3}$, followed by $\mathrm{ACN}(50 \%) / 100 \mathrm{mM} \mathrm{NH} \mathrm{HCO}_{3}(50 \%)$ for $10 \mathrm{~min}$, dehydrated with $100 \% \mathrm{ACN}$ and then air-dried. Finally, samples were digested with $20 \mu \mathrm{L}$ of trypsin $(12.5 \mathrm{ng} / \mathrm{mL}$ $50 \mathrm{mM} \mathrm{NH}_{4} \mathrm{HCO}_{3}$ ), overnight at $37^{\circ} \mathrm{C}$. Proteolytic peptides were extracted twice with ACN (50\%)/formic acid (2\%), dried using a vacuum centrifuge and reconstituted to $10 \mu \mathrm{L}$ with $2 \%$ formic acid for LC-MS/MS analysis.

Peptides were analyzed using a Q Exactive Hybrid Quadrupole-Orbitrap mass spectrometer coupled to a high pressure liquid chromatography unit (Thermo Fisher Scientific, United States). Peptides were separated on a 60 -min reverse phase gradient of $1-50 \%$ solvent B (acetonitrile in $0.1 \%$ formic acid) gradient. In each data collection cycle, one full MS scan (350-2000 m/z) was recorded in the Orbitrap. Subsequently, MS2 analysis was conducted for top 10 most intense ions and were fragmented by higher-energy collisional dissociation (HCD) with following settings; normalized collision energy of $30 \%$, isolation window $3.0 \mathrm{~m} / \mathrm{z}$, maximum ion accumulation time $60 \mathrm{~ms}$ with a dynamic exclusion for $10 \mathrm{~s}$.

Protein identification and quantification was performed on Proteome Discoverer 1.3 (Thermo Fisher Scientific) using Mascot search engine (Perkins et al., 1999). P. aeruginosa strain PAO1 protein sequence database retrieved from GenBank (January 2013) and Pseudomonas Genome Database ${ }^{1}$ and in-silico translated genome databases of PASS4 (Penesyan et al., 2015) were used as the search databases. Database searching against the decoy database was also performed to evaluate the false discovery rate (FDR) of peptide identification. All searches were performed using a static modification for cysteine alkylation and methionine oxidation, acetylation (protein N-term) as dynamic modifications, precursor ion tolerance of $10 \mathrm{ppm}$ and a fragment ion tolerance of $0.02 \mathrm{Da}$ were used. Peptide matches were filtered with peptide and protein FDR $<1 \%$. Then for each identified peptide, its abundance (peak area) was estimated by calculating the area under the extracted ion chromatograms (XIC) curve.

The mass spectrometry proteomics data has been deposited to the ProteomeXchange Consortium via the PRIDE partner repository (Vizcaíno et al., 2014) with the dataset identifier PXD006742.

For statistical analyses, log-transformed quantitative values were used to conduct two-sample $t$-tests comparing protein expression of PASS4 or PAO1 in DNA relative to L-Asparagine using the in-house developed program based on $\mathrm{R}$ modules (Mirzaei et al., 2012; Neilson et al., 2014). Proteins with log fold change \pm 1 and $t$-test $p$-value $<0.05$ were considered to be significantly differentially expressed.

\footnotetext{
${ }^{1}$ www.pseudomonas.com
} 


\section{Functional Analysis}

The transcripts and proteins were mapped to virulence factor annotations and to Cluster of Orthologous Groups (COG) categories obtained from the Pseudomonas Database (Winsor et al., 2016).

\section{Generation of $P$. aeruginosa PASS4 Mutants}

Single colonies of $P$. aeruginosa strain PASS4 were inoculated into $10 \mathrm{ml}$ of LB liquid medium, in triplicate, and grown overnight with constant shaking of $200 \mathrm{rpm}$ at $37^{\circ} \mathrm{C}$. Overnight cultures were centrifuged at $4000 \times g$ for $7 \mathrm{~min}$ at $4^{\circ} \mathrm{C}$ in an Eppendorf centrifuge Model 5430. Once the supernatant was discarded the cells were washed with phosphate buffered saline and spun at $4000 \mathrm{~g}$ for $7 \mathrm{~min}$ at $4^{\circ} \mathrm{C}$. The cells were then resuspended in $5 \mathrm{ml}$ phosphate buffered saline and $2.04 \times 10^{8}$ washed cells were spread on $20 \mathrm{mM}$ GlcNAc. Once spontaneous mutant colonies were obtained, colonies were cultured into M9 minimal salts medium with $100 \mu \mathrm{M}$ calcium chloride $\left(\mathrm{CaCl}_{2}\right)$ and $2 \mathrm{mM}$ magnesium sulfate $\left(\mathrm{MgSO}_{4}\right)$ containing $20 \mathrm{mM}$ GlcNAc. This culture was consecutively subcultured till cells were able to reach an $\mathrm{OD}_{600}=0.7$ within $\sim 35 \mathrm{~h}$.

\section{Whole Genome Sequencing and SNP Analysis of PASS4 Mutants}

Single colonies of $8 \mathrm{P}$. aeruginosa strain PASS4 mutants and the parental PASS4 strain were inoculated into $10 \mathrm{ml}$ of LB liquid medium, in triplicates, from LB agar and grown overnight with constant shaking of $200 \mathrm{rpm}$ at $37^{\circ} \mathrm{C}$. DNA was extracted from the samples according to DNA Isolation DNeasy Blood and Tissue Kit protocol for Gram-negative bacteria (QIAGEN, Germany). Total DNA was quantified using the Nanodrop and submitted to the Ramaciotti Centre for Genomics for paired-end DNA Sequencing on MiSeq v2 platform. Paired-end DNA sequence files obtained from Ramaciotti were assessed for quality using FastQC software (Babraham Bioinformatics, United Kingdom). The pair-end reads for each sample were merged by FLASH-1.2.11 (Magoc and Salzberg, 2011). The merged reads were filtered with the FASTQ quality filter with minimum quality score being 20, and 90 being the minimum percent of bases with a quality score of 20. The reads were then trimmed with FASTQ quality trimmer ensuring minimum length of sequence of 200 and quality thresholds of nucleotide of 28. The FASTQ files were converted to FASTA and then subjected to SNP analysis according to the user guide of kSNP3 software (Gardner et al., 2015).

\section{Growth of $P$. aeruginosa PASS4 in Adenosine}

To identify the lowest concentration of adenosine as a sole carbon source that supported growth of PASS4, growth assays were undertaken in liquid media in M9 minimal salt medium with $100 \mathrm{uM}$ calcium chloride $\left(\mathrm{CaCl}_{2}\right)$ and $2 \mathrm{mM}$ magnesium sulfate $\left(\mathrm{MgSO}_{4}\right)$ supplemented with $0.02 \mathrm{mM}-20 \mathrm{mM}$ adenosine using a broth dilution method essentially as previously described (Wiegand et al., 2008). Cell growth was determined spectrophotometrically.

\section{Complementation of PASS4 Using the pME6032 Vector}

Pseudomonas aeruginosa PASS4 was complemented with an intact $P$. aeruginosa PAO1 purK gene using pME6032 expression vector containing tetracycline resistance marker (Heeb et al., 2002). The pME6032 vector was kindly gifted by Professor Stephan Heeb, University of Nottingham, United Kingdom. Cloning was performed using the In-Fusion HD cloning kit (Takara Bio, United States) following the procedures suggested in the manufacturer's protocol. Briefly, the purK gene was amplified via PCR using the Platinum SuperFi PCR Master Mix (Thermo Fisher Scientific) with $P$. aeruginosa PAO1 genomic DNA as a template, and the primer pair 2_purK_F/R (Table 2). The pME6032 plasmid was linearized using the EcoRI and XhoI restriction enzymes (New England Biolabs) and used in In-Fusion cloning reaction also containing the 5X In-Fusion HD Enzyme Mix and the purified purK PCR fragment. After completion, the reaction mix was used for transformation using E. coli Stellar Competent Cells (Takara Bio, United States) according to the manufacturer's protocol. Petri dishes containing solid LB medium supplemented with $25 \mu \mathrm{g} / \mathrm{ml}$ of tetracycline were used to select and maintain the E. coli transformants. The vector with purK gene insertion was purified from the culture of $E$. coli cells using the Wizard Plus SV Minipreps DNA Purification System (Promega) and the manufacturer's protocol and used to transform the wild type PASS4 strain via electroporation. Overnight culture of PASS4 was inoculated in $2 \times 5 \mathrm{ml}$ fresh LB broth in $50 \mathrm{ml}$ Falcon tubes and incubated overnight, with shaking, at $42^{\circ} \mathrm{C}$, following a previously described method (Kaur et al., 2015). After the incubation the cultures were combined, centrifuged (10 $\mathrm{min}$ at $5000 \mathrm{rpm})$ and the cell pellet resuspended in $5 \mathrm{ml}$ fresh $\mathrm{LB}$ broth containing 6.5 U/ml of Alginate Lyase (Sigma) to break down the excess alginate. The mixture was incubated at $37^{\circ} \mathrm{C}$ for 40 min after which the cells were washed with $1 \mathrm{ml}$ icecold MilliQ water and resuspended in $20 \mu \mathrm{l}$ of sterile icecold water, and $1 \mu \mathrm{l}$ of pME6032_purK plasmid was added (60 ng). The mixture was transferred to cold electroporation cuvette (2 mm gap, Bio-Rad) and electroporated using BioRad MiniPulser (2.5 kV pulse). Immediately after applying the pulse, $1 \mathrm{ml}$ fresh $\mathrm{LB}$ was added to the electroporation mixture, mixed, and incubated at $37^{\circ} \mathrm{C}$ for $3 \mathrm{~h}$. After the incubation the mixture was serially diluted and plated on

TABLE 2 | Primers used in PASS4 complementation experiments.

Primer name Sequence $\left(5^{\prime}\right.$ to $\left.3^{\prime}\right)$

2_purK_F

2_purK_R

Insert_F

CAGGAAACAGAATTCATGAAAATCGGTGTCATCGGTGGC

Insert $R$ TAGTCCGAGGCCTCGAGTCACGCCTCGATCAGC ATTCGTGTCGCTCAAGG CTCGGGTAACATCAAGG 
Petri dishes containing solid LB medium supplemented with $120 \mu \mathrm{g} / \mathrm{ml}$ of tetracycline. The presence of the purK gene in the PASS4 transformants was confirmed using a PCR with the insert_F/R primer pair (Table 2), as well as via Sanger sequencing using the same primers. The sequencing was performed at Macrogen, South Korea. Sequences obtained from Macrogen were aligned with the sequence of the in silico predicted product consisting of pME6032 insertion region and the full-length purK gene, yielding a 100\% match.

\section{Biolog Phenotype Microarray Analysis}

Biolog Phenotype analysis was carried out for P. aeruginosa parental strain PASS4, 8 PASS4 mutants and PASS4 complemented with purK, using PM1 and PM2A MicroPlate ${ }^{\mathrm{TM}}$ Carbon Source Phenotype Microarrays (Biolog, United States) containing a total of 190 substrates (including a range of carbohydrates, carboxylic acids, amino acids, fatty acids, amines, alcohols, polymers, amides and esters) and a negative control for each plate (Bochner et al., 2001). Bacterial cell suspensions (absorbance of 0.07 at $600 \mathrm{~nm}$ ) were prepared in the inoculating fluid (IF-0a, Biolog, United States) and $100 \mathrm{ul}$ of the inoculum was dispensed into each well of the plate using a multichannel pipette. After inoculation, the plates were incubated in the OmniLog incubator/reader (Biolog) for $48 \mathrm{~h}$ at $37^{\circ} \mathrm{C}$. Cell respiration was recorded every $15 \mathrm{~min}$ by a charge-coupled device camera. The changes in the color of inoculated wells due to the conversion of the tetrazolium dye present in the wells into the purple derivative during cell respiration, were plotted over the whole period of incubation yielding kinetic curves representative of the metabolic activity of the strain in the presence of a particular carbon source. Raw values were imported from the OmniLog reader for heatmap generation. For the adenosine-supplemented experiments, $P$. aeruginosa PASS4 was suspended in inoculating fluid supplemented with $2 \mathrm{mM}$ adenosine before dispensing $100 \mu \mathrm{l}$ to each well of the PM1 and PM2A plates (Biolog, United States), which were subjected to Biolog Phenotype Microarray analysis as described above.

\section{REFERENCES}

Ahn, S., Jung, J., Jang, I. A., Madsen, E. L. and Park, W. (2016). Role of Glyoxylate Shunt in Oxidative Stress Response. J. Biol. Chem. 291, 11928-11938. doi: 10.1074/jbc.M115.708149

Anders, S., and Huber, W. (2010). Differential expression analysis for sequence count data. Genome Biol. 11:R106. doi: 10.1186/gb-2010-11-10-r106

Barbier, M., Damron, F. H., Bielecki, P., Suárez-Diez, M., Puchałka, J., Albertí, S., et al. (2014). From the environment to the host: re-wiring of the transcriptome of Pseudomonas aeruginosa from $22^{\circ} \mathrm{C}$ to $37^{\circ} \mathrm{C}$. PLoS One 9:e89941. doi: 10 . 1371/journal.pone.0089941

Bochner, B. R., Gadzinski, P., and Panomitros, E. (2001). Phenotype microarrays for high-throughput phenotypic testing and assay of gene function. Genome Res. 11, 1246-1255.

Craig, L., and Li, J. (2008). Type IV pili: paradoxes in form and function. Curr. Opin. Struct. Biol. 18, 267-277. doi: 10.1016/j.sbi.2007.12.009

Dandekar, A. A., Chugani, S., and Greenberg, E. P. (2012). Bacterial quorum sensing and metabolic incentives to cooperate. Science 338, 264-266. doi: 10. 1126/science. 1227289

Das, T., Kutty, S. K., Tavallaie, R., Ibugo, A. I., Panchompoo, J., Sehar, S., et al. (2015). Phenazine virulence factor binding to extracellular DNA is important

\section{DATA AVAILABILITY}

The datasets generated for this study can be found in GENE EXPRESSION OMNIBUS, GSE100287.

\section{AUTHOR CONTRIBUTIONS}

All authors listed have made a substantial, direct and intellectual contribution to the work, and approved it for publication.

\section{FUNDING}

The project was funded by the Australian Research Council (http://www.arc.gov.au) Super Science grant FS110200026. IP was supported by an Australian Research Council Laureate Fellowship (FL140100021). SK was supported by a Macquarie University Research Excellence Scholarship and the Australian Cystic Fibrosis Research Trust Postgraduate Studentship. The funders had no role in the study design, data collection and analysis, decision to publish, or preparation of the manuscript.

\section{ACKNOWLEDGMENTS}

We thank Professor Stephan Heeb (University of Nottingham, United Kingdom) for kindly gifting us the pME6032 vector. We also thank Karthik Kamath, Deepa Ruth Varkey, Ardeshir Amirkhani, and Dylan Xavier for advice and assistance with the shotgun proteomic experiments.

\section{SUPPLEMENTARY MATERIAL}

The Supplementary Material for this article can be found online at: https://www.frontiersin.org/articles/10.3389/fmicb. 2019.01199/full\#supplementary-material

for Pseudomonas aeruginosa biofilm formation. Sci. Rep. 5:8398. doi: 10.1038/ srep08398

Finkel, S. E., and Kolter, R. (2001). DNA as a nutrient: novel role for bacterial competence gene homologs. J. Bacteriol. 183, 6288-6293.

Flemming, H.-C., and Wingender, J. (2010). The biofilm matrix. Nat. Rev. Microbiol. 8, 623-633. doi: 10.1038/nrmicro2415

Folkesson, A., Jelsbak, L., Yang, L., Johansen, H. K., Ciofu, O., Hoiby, N., et al. (2012). Adaptation of Pseudomonas aeruginosa to the cystic fibrosis airway: an evolutionary perspective. Nat. Rev. Microbiol. 10, 841-851. doi: 10.1038/ nrmicro2907

Gardner, S. N., Slezak, T., and Hall, B. G. (2015). kSNP3.0: SNP detection and phylogenetic analysis of genomes without genome alignment or reference genome. Bioinformatics 31, 2877-2878. doi: 10.1093/bioinformatics/ btv271

Gellatly, S. L., and Hancock, R. E. W. (2013). Pseudomonas aeruginosa: new insights into pathogenesis and host defenses. Pathog. Dis. 67, 159-173. doi: 10.1111/ 2049-632X.12033

Gray, N. (2017). Water Science and Technology an Introduction. 4th Edn. Boca Raton, FL: CRC Press.

Grosso-Becerra, M. V., Croda-García, G., Merino, E., Servín-González, L., MojicaEspinosa, R., and Soberón-Chávez, G. (2014). Regulation of Pseudomonas 
aeruginosa virulence factors by two novel RNA thermometers. Proc. Natl. Acad. Sci. U.S.A. 111, 15562-15567. doi: 10.1073/pnas.1402536111

Hahn, H. P. (1997). The type-4 pilus is the major virulence-associated adhesin of Pseudomonas aeruginosa-a review. Gene 192, 99-108.

Haussler, S., and Fuqua, C. (2013). Biofilms 2012: new discoveries and significant wrinkles in a dynamic field. J. Bacteriol. 195, 2947-2958. doi: 10.1128/JB. 00239-13

He, J., Baldini, R. L., Déziel, E., Saucier, M., Zhang, Q., Liberati, N. T., et al. (2004). The broad host range pathogen Pseudomonas aeruginosa strain PA14 carries two pathogenicity islands harboring plant and animal virulence genes. Proc. Natl. Acad. Sci. U.S.A. 101, 2530-2535.

Heeb, S., Blumer, C., and Haas, D. (2002). Regulatory RNA as mediator in GacA/RsmA-dependent global control of exoproduct formation in Pseudomonas fluorescens CHA0. J. Bacteriol. 4, 1046-1056.

Heeb, S., Fletcher, M. P., Chhabra, S. R., Diggle, S. P., Williams, P., and Cámara, M. (2011). Quinolones: from antibiotics to autoinducers. FEMS Microbiol. Rev. 35, 247-274. doi: 10.1111/j.1574-6976.2010.00247.x

Hogardt, M., and Heesemann, J. (2010). Adaptation of Pseudomonas aeruginosa during persistence in the cystic fibrosis lung. Int. J. Med. Microbiol. 300, 557-562. doi: 10.1016/j.ijmm.2010.08.008

Jorgensen, K. M., Wassermann, T., Johansen, H. K., Christiansen, L. E., Molin, S., Hoiby, N., et al. (2015). Diversity of metabolic profiles of cystic fibrosis Pseudomonas aeruginosa during the early stages of lung infection. Microbiology 161, 1447-1462. doi: 10.1099/mic. 0.000093

Kadurugamuwa, J. L., and Beveridge, T. J. (1995). Virulence factors are released from Pseudomonas aeruginosa in association with membrane vesicles during normal growth and exposure to gentamicin: a novel mechanism of enzyme secretion. J. Bacteriol. 177, 3998-4008.

Kaur, J., Pethani, B. P., Kumar, S., Kim, M., Sunna, A., Kautto, L., et al. (2015). Pseudomonas aeruginosa inhibits the growth of Scedosporium aurantiacum, an opportunistic fungal pathogen isolated from the lungs of cystic fibrosis patients. Front. Microbiol. 6:866. doi: 10.3389/fmicb.2015.00866

Kempes, C. P., Okegbe, C., Mears-Clarke, Z., Follows, M. J., and Dietrich, L. E. (2014). Morphological optimization for access to dual oxidants in biofilms. Proc. Natl. Acad. Sci. U.S.A. 111, 208-213. doi: 10.1073/pnas.1315521110

Kohler, J. E., Zaborina, O., Wu, L., Wang, Y., Bethel, C., Chen, Y., et al. (2005). Components of intestinal epithelial hypoxia activate the virulence circuitry of Pseudomonas. Am. J. Physiol. Gastrointest. Liver Physiol. 288, G1048-G1054. doi: 10.1152/ajpgi.00241.2004

Lee, J., and Zhang, L. (2015). The hierarchy quorum sensing network in Pseudomonas aeruginosa. Protein Cell 6, 26-41. doi: 10.1007/s13238-014-0100-x

Lewenza, S. (2013). Extracellular DNA-induced antimicrobial peptide resistance mechanisms in Pseudomonas aeruginosa. Front. Microbiol. 4:21. doi: 10.3389/ fmicb.2013.00021

Lindsey, T. L., Hagins, J. M., Sokol, P. A., and Silo-Suh, L. A. (2008). Virulence determinants from a cystic fibrosis isolate of Pseudomonas aeruginosa include isocitrate lyase. Microbiology 154, 1616-1627. doi: 10.1099/mic.0.2007/ 014506-0

Luckett, J. C. A., Darch, O., Watters, C., Abuoun, M., Wright, V., Paredes-Osses, E., et al. (2012). A novel virulence strategy for Pseudomonas aeruginosa mediated by an autotransporter with arginine-specific aminopeptidase activity. PLoS pathog. 8:e1002854. doi: 10.1371/journal.ppat.1002854

Magoc, T., and Salzberg, S. L. (2011). FLASH: fast length adjustment of short reads to improve genome assemblies. Bioinformatics 27, 2957-2963. doi: 10.1093/ bioinformatics/btr507

Magoc, T., Wood, D., and Salzberg, S. L. (2013). EDGE-pro: estimated degree of gene expression in prokaryotic genomes. Evol. Bioinform. 9, 127-136. doi: $10.4137 / \mathrm{EBO} . S 11250$

Mall, M. A. (2008). Role of cilia, mucus, and airway surface liquid in mucociliary dysfunction: lessons from mouse models. J. Aerosol. Med. Pulm. Drug Deliv. 21, 13-24. doi: 10.1089 /jamp.2007.0659

Mattick, J. S. (2002). Type IV pili and twitching motility. Annu. Rev. Microbiol. 56, 289-314.

McClure, R., Balasubramanian, D., Sun, Y., Bobrovskyy, M., Sumby, P., Genco, C. A., et al. (2013). Computational analysis of bacterial RNA-Seq data. Nucleic Acids Res. 41:e140. doi: 10.1093/nar/gkt444

Mirzaei, M., Soltani, N., Sarhadi, E., Pascovici, D., Keighley, T., Salekdeh, G. H., et al. (2012). Shotgun proteomic analysis of long-distance drought signaling in rice roots. J. Proteome Res. 11, 348-358. doi: 10.1021/pr200 8779

Mulcahy, H., Charron-Mazenod, L., and Lewenza, S. (2010). Pseudomonas aeruginosa produces an extracellular deoxyribonuclease that is required for utilization of DNA as a nutrient source. Environ. Microbiol. 12, 1621-1629. doi: 10.1111/j.1462-2920.2010.02208.x

Neilson, K. A., George, I. S., Emery, S. J., Muralidharan, S., Mirzaei, M., and Haynes, P. A. (2014). Analysis of rice proteins using SDS-PAGE shotgun proteomics. Methods Mol. Biol. 1072, 289-302. doi: 10.1007/978-1-62703-631-3_21

Oh, J., Li, X.-H., Kim, S.-K., and Lee, J.-H. (2017). Post-secretional activation of protease IV by quorum sensing in Pseudomonas aeruginosa. Sci. Rep. 7:4416. doi: 10.1038/s41598-017-03733-6

Park, S.-J., Kim, S.-K., So, Y.-I., Park, H.-Y., Li, X.-H., Yeom, D. H., et al. (2014), Protease IV, a quorum sensing-dependent protease of Pseudomonas aeruginosa modulates insect innate immunity. Mol. Microbiol. 94, 1298-1314. doi: 10.1111/ mmi. 12830

Pearson, J. P., Pesci, E. C., and Iglewski, B. H. (1997). Roles of Pseudomonas aeruginosa las and rhl quorum-sensing systems in control of elastase and rhamnolipid biosynthesis genes. J. Bacteriol. 179, 5756-5767.

Penesyan, A., Kumar, S. S., Kamath, K., Shathili, A. M., Venkatakrishnan, V., Krisp, C., et al. (2015). Genetically and phenotypically distinct Pseudomonas aeruginosa cystic fibrosis isolates share a core proteomic signature. PLoS One 10:e0138527. doi: 10.1371/journal.pone.0138527

Perkins, D. N., Pappin, D. J. C., Creasy, D. M., and Cottrell, J. S. (1999). Probability-based protein identification by searching sequence databases using mass spectrometry data. Electrophoresis 20, 3551-3567.

Petrova, O. E., and Sauer, K. (2009). A novel signaling network essential for regulating Pseudomonas aeruginosa biofilm development. PLoS Pathog. 5:e1000668. doi: 10.1371/journal.ppat.1000668

Pinchuk, G. E., Ammons, C., Culley, D. E., Li, S.-M. W., McLean, J. S., Romine, M. F., et al. (2008). Utilization of DNA as a sole source of phosphorus, carbon, and energy by Shewanella spp.: ecological and physiological implications for dissimilatory metal reduction. Appl. Environ. Microbiol. 74, 1198-1208

Rampioni, G., Falcone, M., Heeb, S., Frangipani, E., Fletcher, M. P., Dubern, J.-F., et al. (2016). Unravelling the genome-wide contributions of specific 2-alkyl4-quinolones and PqsE to quorum sensing in Pseudomonas aeruginosa. PLoS Pathog. 12:e1006029. doi: 10.1371/journal.ppat.1006029

Reis, R. S., Pereira, A. G., Neves, B. C., and Freire, D. M. G. (2011). Gene regulation of rhamnolipid production in Pseudomonas aeruginosa -a review. Bioresour. Technol. 102, 6377-6384. doi: 10.1016/j.biortech.2011.03.074

Robinson, C. (2013). Utilization of Mucin Sulfate by Pseudomonas aeruginosaImportance for Cystic Fibrosis. Ph.D thesis. Manchester: University of Manchester.

Sadikot, R. T., Blackwell, T. S., Christman, J. W., and Prince, A. S. (2005). Pathogen-host interactions in Pseudomonas aeruginosa pneumonia. Am. J. Respir. Crit. Care Med. 171, 1209-1223.

Smith, D. J. (2015). Investigating the Host and Bacterial Factors in Cystic Fibrosis that Promote Persistence of Infection in the Lung. Ph.D Thesis. Brisbane: The University of Queensland.

Sonnleitner, E., Valentini, M., Wenner, N., Haichar, F. Z., Haas, D., and Lapouge, K. (2012). novel targets of the CbrAB/Crc carbon catabolite control system revealed by transcript abundance in Pseudomonas aeruginosa. PLoS One 7:e44637. doi: 10.1371/journal.pone.0044637

Stover, C. K., Pham, X. Q., Erwin, A. L., Mizoguchi, S. D., Warrener, P., Hickey, M. J., et al. (2000). Complete genome sequence of Pseudomonas aeruginosa PAO1, an opportunistic pathogen. Nature 406, 959-964.

Thaysen-Andersen, M., Venkatakrishnan, V., Loke, I., Laurini, C., Diestel, S., Parker, B. L., et al. (2015). Human neutrophils secrete bioactive paucimannosidic proteins from azurophilic granules into pathogen-infected sputum. J. Biol. Chem. 290, 8789-8802. doi: 10.1074/jbc.M114.631622

Tjaden, B. (2015). De novo assembly of bacterial transcriptomes from RNA-seq data. Genome Biol. 16:1. doi: 10.1186/s13059-014-0572-2

Tralau, T., Vuilleumier, S., Thibault, C., Campbell, B. J., Hart, C. A., and Kertesz, M. A. (2007). Transcriptomic analysis of the sulfate starvation response of Pseudomonas aeruginosa. J. Bacteriol. 189, 6743-6750.

Turnbull, L., Toyofuku, M., Hynen, A. L., Kurosawa, M., Pessi, G., Petty, N. K., et al. (2016). Explosive cell lysis as a mechanism for the biogenesis of 
bacterial membrane vesicles and biofilms. Nat. Commun. 7:11220. doi: 10.1038/ ncomms 11220

van der Ploeg, J. R., Weiss, M. A., Saller, E., Nashimoto, H., Saito, N., Kertesz, M. A., et al. (1996). Identification of sulfate starvation-regulated genes in Escherichia coli: a gene cluster involved in the utilization of taurine as a sulfate source. J. Bacteriol. 178, 5438-5446.

Vankeerberghen, A., Cuppens, H., and Cassiman, J.-J. (2002). The cystic fibrosis transmembrane conductance regulator: an intriguing protein with pleiotropic functions. J. Cyst. Fibros. 1, 13-29.

Vizcaíno, J. A., Deutsch, E. W., Wang, R., Csordas, A., Reisinger, F., Rios, D., et al. (2014). ProteomeXchange provides globally coordinated proteomics data submission and dissemination. Nat. Biotechnol. 32, 223-226.

Wagner, V. E., and Iglewski, B. H. (2008). P. aeruginosa biofilms in CF Infection. Clin. Rev. Allergy Immunol. 35, 124-134. doi: 10.1007/s12016-0088079-9

Wang, G., Huang, X., Li, S., Huang, J., Wei, X., Li, Y., et al. (2012). The RNA Chaperone $\mathrm{Hfq}$ regulates antibiotic biosynthesis in the rhizobacterium Pseudomonas aeruginosa M18. J. Bacteriol. 194, 2443-2457. doi: 10.1128/JB. 00029-12

Wessel, D., and Flugge, U. I. (1984). A method for the quantitative recovery of protein in dilute solution in the presence of detergents and lipids. Anal. Biochem. 138, 141-143.

Whiteley, M., Lee, K. M., and Greenberg, E. P. (1999). Identification of genes controlled by quorum sensing in Pseudomonas aeruginosa. Proc. Natl. Acad. Sci. U.S.A. 96, 13904-13909.

Wiegand, I., Hilpert, K., and Hancock, R. E. (2008). Agar and broth dilution methods to determine the minimal inhibitory concentration (MIC) of antimicrobial substances. Nat. Protoc. 3, 163-175. doi: 10.1038/nprot. 2007.521

Wilson, R., Sykes, D. A., Watson, D., Rutman, A., Taylor, G. W., and Cole, P. J. (1988). Measurement of Pseudomonas aeruginosa phenazine pigments in sputum and assessment of their contribution to sputum sol toxicity for respiratory epithelium. Infect. Immun. 56, 2515-2517.

Winsor, G. L., Griffiths, E. J., Lo, R., Dhillon, B. K., Shay, J. A., and Brinkman, F. S. (2016). Enhanced annotations and features for comparing thousands of Pseudomonas genomes in the Pseudomonas genome database. Nucleic Acids Res. 44, D646-D653. doi: 10.1093/nar/gkv1227

Winstanley, C., O’Brien, S., and Brockhurst, M. A. (2016). Pseudomonas aeruginosa evolutionary adaptation and diversification in cystic fibrosis chronic lung infections. Trends Microbiol. 24, 327-337. doi: 10.1016/j.tim.2016.01.008

Yeung, A. T. Y., Janot, L., Pena, O. M., Neidig, A., Kukavica-Ibrulj, I., Hilchie, A., et al. (2014). Requirement of the Pseudomonas aeruginosa CbrA sensor kinase for full virulence in a murine acute lung infection model. Infect. Immun. 82, 1256-1267. doi: 10.1128/IAI.01527-13

Zaoui, C., Overhage, J., Lons, D., Zimmermann, A., Musken, M., Bielecki, P., et al. (2012). An orphan sensor kinase controls quinolone signal production via MexT in Pseudomonas aeruginosa. Mol. Microbiol. 83, 536-547. doi: 10.1111/j. 1365-2958.2011.07947.x

Zhang, Y., Morar, M., and Ealick, S. E. (2008). Structural biology of the purine biosynthetic pathway. Cell Mol. Life Sci. 65, 3699-3724.

Conflict of Interest Statement: The authors declare that the research was conducted in the absence of any commercial or financial relationships that could be construed as a potential conflict of interest.

Copyright (c) 2019 Kumar, Penesyan, Elbourne, Gillings and Paulsen. This is an open-access article distributed under the terms of the Creative Commons Attribution License (CC BY). The use, distribution or reproduction in other forums is permitted, provided the original author(s) and the copyright owner(s) are credited and that the original publication in this journal is cited, in accordance with accepted academic practice. No use, distribution or reproduction is permitted which does not comply with these terms. 